\title{
The Impact of Parental Socioeconomic Status on Students' Academic Achievement in Secondary Schools in Tanzania
}

\author{
Orestes Silverius Kapinga ${ }^{1, *}$ \\ ${ }^{1}$ Faculty of Education, Mkwawa University College of Education, P.O. Box 2513, Iringa, \\ Tanzania \\ *Correspondence: Tel: 255-769-762-641 E-mail: orestes.katopu@gmail.com
}

Received: October 6, 2014 Accepted: December 4, 2014 Published: December 19, 2014

doi:10.5296/ije.v6i4.6420ＵRL: http://dx.doi.org/10.5296/ije.v6i4.6420

\begin{abstract}
The aim of the study was to assess the impact of parental socioeconomic status (SES) on students' academic achievement in secondary schools. Two research objectives guided the study. They are: How does parents' occupation, income, level of education and home environment affect students' academic achievement in secondary schools? To what extent does parental involvement in education of their children enhance academic achievement? The study employed a qualitative research approach informed by a case study research design. A purposive sampling technique was used to obtain 60 informants drawn from amongst parents, teachers and students. The data were collected through semi-structured interviews and focused group discussions. Data were analysed qualitatively using thematic analysis.

The study found that majority of the students from the selected secondary schools are from low SES. The study established that there is a close relationship between SES and academic achievement. The study further found that majority of the parents are not involved in the learning of their children as well as in the school improvement programmes. The study recommends that the government should review the policy of cost sharing and make it free to o-level students especially to low SES students. In addition, schools should have professional guidance and counsellors to help students with problems to reduce the gap between low and high SES.
\end{abstract}

Keywords: academic achievement, socioeconomic status, secondary schools, Tanzania 


\section{Introduction}

The association between socioeconomic status (SES) and students' academic achievement has been documented among many populations (Ahmad \& Khan, 2012; Ngorosho, 2011; Ahawo, 2009; Otula, 2007). For example, Ahmad and Khan (2012) and Ahmar and Anwar (2013) found a significant relationship between parental socioeconomic conditions and academic achievements of the children in secondary examination and it was concluded that the majority of children whose parents have better socioeconomic conditions performed better in secondary examination as compared to those children whose parents had low socioeconomic conditions. Ngorosho (2011) found five key variables (fathers' and mothers' education, house wall material, light source, and the number of books for school subjects in the homes) as significant indicators of home environment in rural eastern Tanzania. Ahawo (2009) found that in modern society, parents' influence plays a very important role in the academic life of a student. According to Otula (2007), effective provision of secondary education is hampered by SES of parents. Parents from low SES fail to provide their children with basic requirements for schools including books, pens or pencils, proper nutrition and supportive environment for learning.

It is generally accepted that parental SES has an impact on students' academic achievement. For example, children whose parents are of high educational scales have a far better statistical chance of participating in secondary education (Halsey, Health \& Ridge, 1980). Otula (2007) supported this by stating that effective learning involves partnership of students, teachers and parents. Parents' level of education has a multifaceted impact on children's ability to learn in school. In one study, children whose parents had primary school education or less were more than three times likely to have low test scores or grade repetition than children whose parents had at least secondary schooling (Goodwin \& Goodwin, 1995). In the same study, it was also found that parents' level of education not only influenced parent-child interaction related to learning but also the need for help at home that often comes at the expense of keeping children in school

Parents with little formal education may also be less familiar with the language used in school, limiting their ability to support learning and participate in school related activities (Omoraka, 2001). Although many constraints exist, schools can play a pivotal role in helping parents to enhance the home curriculum and improve the quality of parental involvement in their children's education. The strategies include for example, schools collaborating with organizations that can affect parenting in the pre-school years such as public health providers and non-governmental organizations (NGOs). Successful attempts to increase parental involvement have taken place around the world. One example is the creation of student newspapers in China (Majoribanks, 2001). Such newspapers exist at different levels of the education system in urban as well as rural zones. The result is that pupils and parents in urban areas have the possibility to read, which is of benefit in particular to the otherwise disadvantaged rural families (Goodwin \& Goodwin, 1995).

According to MoEVT (2012), secondary schools in Tanzania experience a high rate of drop out. For example in 2012 a total of 94990 students dropped from studies for various reasons which increased from 76002 in 2011 (URT, 2012; 2013). Statistics indicate that $72.2 \%$ of those who 
dropped was accounted by truancy in 2011 and $76.1 \%$ in 2012, followed by the proportion of those who were unable to meet basic needs which accounted for $13.9 \%$ in 2011 and $12.9 \%$ in 2012 (URT, 2011; 2012). The data suggests that many children come from families which cannot afford to meet school needs which is an aspect of SES. The data further show that the majority of students who dropped from schools were in ordinary secondary school level and most of them were form two students. In view of this, the phenomenon needs an intervention through systematic and comprehensive studies.

\subsection{Aim of the study}

The overall aim of this study was to assess the impact of parental socioeconomic status on students' academic achievement in secondary schools.

\subsubsection{Specific objectives}

The specific objectives of this study were:

i. To assess the impact of parents' occupations, income, level of education and home environment on students' academic achievement in secondary schools.

ii. To examine the extent to which parental involvement in their children's education enhances academic achievement in secondary schools.

\subsubsection{Research questions}

The following research questions guided this study:

i. How does parents' occupation, income, level of education and home environment affect students' academic achievement in secondary schools?

ii. To what extent does parental involvement in education of their children enhance academic achievement?

\section{Literature review}

The present study was guided by the sociocultural theory. The sociocultural theory has profound implications for teaching, schooling, and education. The influence of sociocultural theory on education has resulted in a broadening of our understanding of how and what children learn. A key feature of this emergent view of human development is that higher order functions develop out of social interaction (Hamer, 2005). According to Fleer (2002) sociocultural theory challenges us to widen our perspective beyond that of the individual and of knowledge and meaning in isolation. Vygotsky's sociocultural theory of human learning describes learning as a social process and the origination of human intelligence in society or culture. The major theme of Vygotsky's theoretical framework is that social interaction plays a fundamental role in the development of cognition.

SES is a broad construct representing a family's access to social and economic resources (Bradley \& Corwyn, 2002). Empirical investigations most frequently assess SES using 
measures of three key variables: family income, parents' educational levels and parents' occupations (Bradley \& Corwyn, 2002). Other measures of SES include household composition, income to poverty ratio and home ownership status (Jeynes, 2002). An examination of SES as a variable reveals inequities in access to and distribution of resources. In the context of the present study, SES is defined as consisting of parents' income, parents' educational levels and parents' occupations.

Research has found that there is a high risk of educational underachievement for children who are from low income housing circumstances (Arias \& de Vos, 1996). Children from low SES family are at a higher risk than advantaged children for retention in their grades, special deleterious placements during the school's hours and even not completing their secondary school education. Schools in poverty stricken areas have conditions that hinder children from learning in a safe environment (Arias \& de Vos, 1996). In addition, poor children are much more likely to suffer from hunger, fatigue, irritability, headaches, ear infections, flu and colds. These illnesses could potentially restrict a child's focus and concentration. Students from high SES families have favourable environment and availability of educational materials (Wood, 2002). Moreover, students from high SES families have enough time to stay at school as their parents are able to pay school fees and other contributions (Best \& Kahn, 2006). Therefore, it seems that children whose families have income below the poverty line are far less successful educationally than children who live in families with income above the poverty line.

The trend of students to accelerate in academics is connected to the educational status of the parents or relatives in the homes in which a child grows up. Bandura (1977) revealed that children who played truant or dropped out of school belonged to not only economically poor families but also to the parents with little formal education. It was found that educated parents tend to motivate their children in matters related to schooling and support them academically. Educated parents have greater influence on the academic achievement of their children. Nevertheless, uneducated parents' influence on academic achievement of their children is low. In addition, parents' attitudes and involvement towards their children's learning vary according to educational level (Mganga \& Mizambwa, 1997).

SES hampers effective provision of secondary education. Parents from low economic status fail to provide their children with basic requirement for school including books, maps, charts, pens or pencils, proper nutrition and supportive environment for learning. Healthy development in early childhood, especially during the first three years of life, plays an important role in providing the basis for a healthy life and a successful formal school experience (Best \& Kahn, 2006). Adequate nutrition is critical for normal brain development in the early years. Prevention of infections, diseases and injury prior to school enrolment are also critical to the early development of a quality learner. In one study, children whose parents had primary school education or less were more than three times as likely to have low test scores or grade repetition than children whose parents had at least secondary schooling (Booth, 1996).

Bandura (1977) argues that students of all ethnic groups, from middle and high SES show average achievement on test scores and stay in school longer than low SES students. Halsey, Health and Ridge (1980) pointed out that parents and communities have been contributing to 
the education expenses of their children in the form of school fees, uniforms, physical infrastructures, school supplies and managerial service. However, children from low SES have problems in meeting financial obligations and lack of school fees is one of the factors contributing to the problem of dropouts among secondary school students. Therefore, students from low SES families lack consistent attendance to school. Likewise, Krishnawami (1993) noted that students from low SES may come to believe that doing well in school is impossible, as many friends and relatives never finished school.

According to Rwezahura (2005) in low socioeconomic environment children may have socialization experiences that promote competitiveness and reliance on external support. Woolfolk (2004) supports by arguing that because low SES students may wear old clothes, speak in dialect or be less familiar with books and school activities, teachers and other students may assume that those students are not bright and teachers may avoid calling them to answer questions in the classroom to protect them from embarrassment of giving wrong responses. This makes these students less attentive and do not concentrate on what is being taught, and in the end, they come to believe that they are not very good at schoolwork. This situation makes them perform poorly in the subjects and sometimes drop out from school because they are affected psychologically. Bandura (1977) points out that some low SES families cannot afford nutritional meals for their children. Poor nutrition in the early developmental years is associated with lower intelligent quotient (IQs), poorer attention to studies and lower memory ability. Children from high and middle SES settle into school environment very readily, since they have all the school requirements. This reflects concentration towards the schoolwork. On the other hand, low SES children find the school environment very strange and hence lack of concentration to schoolwork, which may lead to poor performance. According to Halsey, Health and Ridge (1980) low SES parents tend to have lower aspirations, allowing their children to drift into classes and relying on the decisions of others.

\section{Methodology}

The study employed a qualitative research approach to obtain in-depth and breadth information. The study adopted a case study research design. The intention was to conduct an in-depth investigation on how parental SES influences students' academic achievement in secondary schools. Furthermore, the case study design was preferred because it allowed an exploration of a situation using multiple methods of data collection (Creswell, 2003). The study was conducted in Iringa Municipality. The sample of the study was drawn from three secondary schools namely Lugalo, Highlands and Kwakilosa in Iringa Municipality. Lugalo Secondary School is a public and one of the oldest and well established schools in Iringa Municipality and accommodates students from both low and high SES families. The Highlands Secondary School is a private school which mainly accommodates children from high SES families. Kwakilosa Secondary School is a community school located in a typical low SES locality and accommodates children from the locality. Parents were included in the sample because they are directly responsible for paying various school contributions and fees. Therefore, parents were rich informants on their SES, and how it affected the educational achievement of their children. 
Students were immediate victims of the SES of their parents, thus, they were rich informants and provided information on the impact of income on learning process in schools. Teachers were involved in the study because they are involved in the day to day learning of students. They are also involved in monitoring school attendance as well as assessment and evaluation of the students. The sample size for this study consisted of 60 respondents (Table 1).

Table 1. Sample composition by Category and Sex

\begin{tabular}{llll}
\hline Categories of Respondents & \multicolumn{3}{l}{ Sex of the Respondents } \\
\cline { 2 - 4 } & Males & Females & Total \\
\cline { 2 - 4 } Teachers & 03 & 03 & 06 \\
Parents & 03 & 03 & 06 \\
Students & 24 & 24 & 48 \\
Total & 30 & 30 & 60 \\
\hline
\end{tabular}

\subsection{Data collection and analysis}

In this study, documentary review was employed to facilitate collection of information from official documents available in the schools. The documents included school reporting books, class attendance registers, borrowing books, and examination results documents. These documents helped to collect data on the role of parents' SES on students' achievement. The documentary search provided insights into the impact of SES by cross validating and augmenting evidences obtained from other methods and sources of data (Yin, 1994).

Semi-structured interviews were used to collect reliable data about the study. Semi-structured interviews enabled participants to raise and pursue issues and matters that might not be included in the pre-devised schedules such as questionnaires (Cohen, Manion \& Morrison, 2007; Cohen, Manion \& Morrison, 2000; Kothari, 2004; Best \& Khan, 1998). In addition, the semi-structured interviews provided interactive relationship between the researcher and informants which resulted into yielding first-hand and in-depth information. The interview sessions were held between the researcher, parents and teachers. From these respondents, the researcher got information on the role of parental SES on students' academic achievement in secondary schools. The researcher administered interviews in person after visiting them for prior notice. All interviews were conducted in ventilated rooms for the purpose of comfort and confidentiality. With the consent of respondents, voice recorder prepared for such purpose recorded all interviewees' responses.

Focused group discussion (FGD) was conducted among students. The discussion was divided into two groups, which involved eight students each. The discussion took place after normal class hours to avoid disrupting normal classroom teaching. For enhancing the validity of information, the focused group discussions were conducted in a classroom. With the participants' consent, the focused group discussions were audio taped. The researcher triangulated the methods of data collection and respondents using simple and clear language. The qualitative data collected through interviews and focused group discussion were subjected to thematic content analysis. The process of content analysis involved categorizing data, 
grouping them into themes and units (Kothari, 2004). First, the researcher prepared the collected data for analysis. Second, the researcher organized the material into segments of texts and generated themes for analysis. Third, the researcher analysed the findings and made an interpretation of the data.

\section{Results and discussion}

The study was guided by two research questions. The first research question aimed at assessing how parents' occupation, income, level of education and home environment affect students' academic achievement in secondary schools. The second research question explored the involvement of parents to their children's academic achievement in secondary schools. Findings for both research questions are presented in the subsequent sections.

\subsection{Impact of parental SES on students' academic achievement}

The first research question sought to assess how parents' occupations, income, level of education and home environment affect students' academic achievement in secondary schools.

\subsubsection{Parents' educational level}

Through interviews with parents, the findings revealed that the level of parents' education influenced students' achievement in school. It was found that parents who reached a certain level of education had the ability to assist children doing school given homework. The findings also indicated that parents who reached secondary education or higher education level knew the need of buying books, models and maps for their children. One female parent made the following statement:

\section{...I know my children are supposed to do homework at home in evenings and weekends. I am responsible to give them books and other requirements, I assist them adequately! I share with them, and encourage them to work hard in studies. I share experience of my personal accounts when I was a student and tell them about respected scholars and academicians in the world (Parent, School A).}

Booth (1996) in a study on truancy and school dropout revealed that children who played truancy or dropped out of school belonged to not only economically poor families, but also to the parents with little formal education. It was further found that educated parents tend to motivate their children in matters related to schooling and support them academically.

\subsubsection{Parental occupations}

The researcher sought to find out whether parents' occupations influenced students' academic achievement or not. The data collected through focused group discussion with students indicated different occupations of their parents. The occupations included nurses, teachers, medical doctors, carpenters, electricians, masonry, businessmen and women, and peasants. Education support to their children varied over the occupations of the parents. Findings from the interviews with students and teachers revealed that parents from formal occupations had better position and assurance of helping students at home than those from the informal 
occupations. Formal occupations had monthly salaries that were used to buy books and stationery for their children. Informal occupations such as peasantry, masonry and carpentry were the main self-employment occupations which had no guarantee of getting basic requirements. A student made the following statement:

My parents are farmers and depend on harvests of the farms. The harvest depends on the capital invested in buying fertilizers, and seeds. We are not like students whose parents are nurses, teachers, doctors and others in public sectors...we really suffer, our parents are poor, and they just cultivate for subsistence and not selling for profit (Student, School C).

Booth (1996) supports that negative achievement of students is correlated with low (SES) of parents because it hinders the individual in gaining access to learning resources. Low SES level strongly affects the achievement of students, dragging them down to a lower level. It is also observed that economically disadvantaged parents are less able to afford the cost of education of their children at higher levels, and consequently, they do not work at their fullest potential.

\subsubsection{Parental income}

Research findings have shown that economic factors are major causes for persistent mass failure in schools. Interviews held with informants revealed that poverty is a contributing factor for negative developmental and academic outcomes. Children growing up in poverty may suffer from more developmental delays and learning disabilities than children from higher income homes. This may cause an impact on the overall learning and school achievement. One teacher claimed that:

Home environment is a determinant factor for students' achievement in school. Home environment is not much appropriate in some families due to poverty. Poverty makes difficulty for parents to provide requirement for their children like books, pens, ink, pencils, lumps, water and food that are significant for learners. ....listen...we have vulnerable children who are taken care of by step parents, elders and grandmothers. Those guardians do not make any emphasis on schooling (Teacher, School C).

This observation concurs with Halsey, Health and Ridge (1980) who argued that parents have different emphases to the interests of their children. It, thus, appears that career modelling from parents could make a noticeable impression on children's development. For example, mothers who engage in jobs like hairdressing, sewing, petty trading, farming, catering among others, are more likely to influence children to prefer parents' activities to education.

\subsubsection{Home environment}

In this part, the study examined the availability of learning facilities such as books, desks, computers, charts, maps and electricity at home. The findings revealed that the availability of these items varied with SES. Parents with high SES afforded to supply some of these items to their children while parents of low SES did not. These had an impact of learning for students. One respondent affirmed that: 
My parent is just a carpenter; I live in a house without electricity and water. During night, I use kerosene lamp to revise and do homework. Due to low income of my parents, they fail to buy kerosene for us. When it happens so, we just sleep without doing homework or revision. On the other hand, lack of water poses another challenge to me at home. Before doing homework, I walk to next houses so as to fetch water, that, it is done usually (Student, School A).

The quotation above indicates that family with low income do not create home learning environment for their children. However, family with high income afford to create home learning environment by supplying them books, electricity, water, maps and models. Halsey, Health and Ridge (1980) support the findings that the environment at home can have a significant impact on the schooling of children both positively and negatively. The environment at home can reinforce what children learn at school. Materials and resources found at home can promote the learning of children at home. The presence of reading materials at home for example, reinforces reading skills acquired at school. It is therefore, encouraged that parents should be involved themselves in the education of their children.

\subsection{Parental involvement in children's education}

The second research question assessed the involvement of parents in their children's education. In particular, the question examined the kind of involvement, support and encouragement offered to students. Relevant information was obtained through interviews, focus group discussion and documentary review. The findings are presented and discussed in the subsequent subsections.

\subsubsection{Home involvement}

The home is an important agent of socialization. Before children enter school, they would have already learnt specific cultural norms and expectations from their homes and communities. In this study, direct observations of homes were made in order to identify factors within the home that may affect children education. In particular, the study was interested in investigating how resources necessary for schooling were distributed between boys and girls, the division of labour in the homes and how it affected school attendance of girls relative to boys and finally cultural practices and values within the homes that affected secondary education.

\subsubsection{Learning environment within homes}

In this part, the study examined the availability of learning facilities such as books, desks, computers, charts, maps and electricity. The findings revealed that availability of these items varied with SES. Parents with high SES afforded to supply some of these items to their children while parents of low SES failed. One student respondent affirmed that:

My parent is just a carpenter; I live in a house without electricity and water. During night, I use kerosene lamp to revise and do homework. Due to low income of my parents, they fail to buy kerosene for us. When it happens so, we just sleep without doing homework or revision. On the other hand, lack of water poses 
another challenge to me at home. Before doing homework, I have to fetch some water, that, it is done usually (Student, School A).

The quotation above indicates that families with low income do not create home learning environment for their children. However, families with high income afford to create home learning environment by supplying them books, electricity, water, maps and models. Halsey, Health and Ridge (1980) support by pointing out that the environment at home can have a significant impact on the schooling of children both positively and negatively. The environment at home can reinforce what children learn at school. Materials and resources found at home can promote the learning of children at home.

\subsubsection{Availability of learning facilities}

Households observed had variety of places that were used by students for studying. The study was interested in assessing whether boys and girls used these equally. The most frequently used items for studying were chairs, tables, verandas and beds. Less frequently used items were mats, stools, trees and open spaces. It was observed that in most of the homes both boys and girls used these facilities for studying. However in a few cases, it was observed that boys had more access to these facilities than girls did.

Students and parents were also asked to say on the contribution of learning facilities at home. Around $61 \%$ of the students said that learning facilities available at home environment were not utilized effectively because parents were not fully involved. Parents were noticed to divide household responsibilities, which made them tried to participate in their homework. In areas like Kwakilosa, students said that they were involved in petty business, which avoided them to spend time effectively and utilize the resources available at home. Parents who participated in interviews supported the observation. This helps them learn both home chores with school lessons concurrently. They emphasized that students will become parents in the near future, it is not correct to exempt them from household responsibility as they prepare for adult work.

Students need to learn also other household responsibilities. These prepare them for adult activities. Even in school, there are extra curriculum activities in which students are taught sports, farm domestic works and vocational education. It is, therefore, noticeable that things parents direct their children to do it not over burden them, but train them (Parent, Kwakilosa).

The quotation above indicates that despite the availability of facilities in high SES families, students did not use them. This is because parents provided them other household responsibilities.

\subsubsection{Parents' motivation and encouragement}

The study in this part examined the extent to which parents motivated and encouraged their children in studying. The data collected through focus group discussion from the students revealed that motivation and encouragement varied against parents' SES. It was noted that 
parents with high SES motivated and encouraged their children by awarding them when they passed examination. One student reported as follows:

My father gives me rewards when I emerge between one and ten best students in examination. Last time I emerged the fifth in the internal examination; he bought me a dress, watch and shoes. He has promised me to visit Ruaha National Park when I lift to the top position this term. I work hard, and he helps me in my homework when he is back from his office (Student, School A)

The quotation indicates that parents with high education and formal occupation know the importance of education to their children. Contrary to this, parents with low educational level do not find the importance of education to their children particularly girls' students. One parent who was interviewed on the involvement of his daughter's education commented that educating girls is loosing of money since instead of bringing home good score she brings home pregnancy.

\section{Conclusions and recommendations}

The overall aim of this study was to assess the impact of parental SES on students' academic achievement in secondary schools. The study built on the basis that SES affects the achievement of students in schools. The findings of the study also expected to inform school administrators and teachers on how parental SES influences students' achievements in their schools. In addition, the findings expected to inform parents on how their SES and involvement on their children in school matters influence academic achievement. Presently in the study area, and the country at large, there have been a number of innovations within the school sector. Currently in the country there is the implementation of Secondary Education Development Plan II which whose objectives to expand the access to secondary education and make secondary education more accessible to enable children from poor homes benefit and achieve the necessary education that will enable them participate functionally and actively in the development of their community and the country at large. Based on the result of the analysis, it was discovered that parents' SES has a significant relationship between parent's SES and family type on female student's school dropout in the study area. There is the urgent need for both public and private sector participation in the planning, provision, implementing, supervision, monitoring and funding of educational facilities within the study area.

\section{References}

Ahawo, H. (2009). Factors Enhancing Student Academic Performance in Public Mixed Day Secondary Schools in Kisumu East District Kenya. Unpublished M.Ed. Thesis Maseno.

Ahmad, I., \& Khan, N. (2012). Relationship between parental socio-economic conditions and students' academic achievements: A case of district dir, Timergara, Pakistan. Global Advanced Research Journal of Educational Research and Review, 1(7), 137-142. http://garj.org/garjerr/index.htm. 
Ahmar, F., \& Anwar, E. (2013). Socio Economic Status and its Relation to Academic Achievement of Higher Secondary School Students. IOSR Journal of Humanities and Social Science (IOSR-JHSS), 13(6), 13-20.

Arias, E., \& De Vos, S. (1996). Using Housing Items to Indicate Socioeconomic Status: Latin America. Journal of Social Indicators Research, 38, 53-60. http://dx.doi.org/10.1007/BF00293786.

Bandura, A. (1977). Self-efficacy: Toward a Unifying Theory of Behavioural change. Psychological Review, 84(2), 191-215. http://dx.doi.org/10.1037/0033-295X.84.2.191

Best, J. K., \& Khan, J. V. (1998). Research in Education. Boston: Alyn and Bacon.

Booth, M. Z. (1996). Parental Availability and Academic Achievement among Swazi Rural Primary School Children. Comparative Education Review, 40, 250-263. http://dx.doi.org/10.1086/447384

Bradley, R. H., \& Corwyn, R. F. (2002). Socioeconomic Status and Child Development. Annual Review of Psychology, 3(1), 371-399. http://dx.doi.org/10.1146/annurev.psych.53.100901.135233

Cohen, L., Manion, L., \& Morrison, K. (2000). Research methods in education(5 ${ }^{\text {th }}$ Ed.). London: Routledge Falmer.

Cohen, L., Manion, L., \& Morrison, K. (2007). Research methods in education $\left(6^{\text {th }} \mathrm{Ed}\right)$. London: Routledge. http://dx.doi.org/10.4324/9780203224342

Creswell, J. W. (2003). Research Design, Qualitative, and Quantitative and Mixed Approach $\left(2^{\text {nd }} E d\right)$. London: Sage Publications.

Fergusson, M., D., Horwood, J., L., \& Boden, M. J. (2008). The transmission of social inequality: Examination of the linkages between family socioeconomic status in childhood and educational achievement in young adulthood. Research in Social Stratification and Mobility, 26, 277-295. http://dx.doi.org/10.1016/j.rssm.2008.05.001

Fleer, M. (2002). Sociocultural theory: rebuilding the theoretical foundations of early childhood education. Delta: Policy and Practice in Education, 54(1\&2), 105-119.

Goodwin, W. L., \& Goodwin, L. (1995). Understanding Qualitative and Quantitative Research in Early Childhood. New York: Teachers College Press.

Halsey, A. H., Health, A. F., \&. Ridge, J. M. (1980). Origins and destinations: Family, Class and Education in Modern Britain. Oxford: Clarendon Press.

Hamer, J. (2005). Exploring literacy with infants from a sociocultural perspective. New Zealand Journal of Teachers' Work, 2(2), 70-75.

Jeynes, W. H. (2002). Examining the effect of parental absence on the academic achievement of adolescents: The challenge of controlling for family income. Journal of family and Economic issues, 23(2). http://dx.doi.org/10.1023/A:1015790701554. 
Kothari, C. R. (2004). Research Methodology: Methods and Techniques. New Delhi: New Age International $(\mathrm{P})$ Limited.

Krishnawami, O. R. (1993). Methodology of Research in Social Sciences. New Delhi: Himalaya Publishers.

Majoribanks, K. (2001). Sibling Dilution Hypothesis. A regression Surface Analysis. Physiological Report Retrieved on November, 10, 2009. http//www.ncbi.n/m.nik.groped

Mganga, B. C., \& Mizambwa, E. (1997). Parents' Involvement in Primary Education in Tanzania. A Case Study of Morogoro Municipality. Unpublished M.Ed. Thesis. Morogoro: Åbo Akademi University.

Ngorosho, D. (2011). Literacy Skills of Kiswahili Speaking Children in Rural Tanzania: The role of home environment. Vasa: Åbo Akademi University.

Omoraka, S. (2001). The Effect of Gender, Socioeconomic Status and school location Retrieved $26^{\text {th }}$ August, 2010 from http/www/fundartticles.com/p/articles

Otula P. A. (2007). Mastery of Modern School Administration. Unpublished Work. Roy-Campbell, Z. M. 1995. Does Medium of Instruction Really Matter? The Language Question in Africa: The Tanzanian Experience. Utafiti New Series, 2, 22- 39.

Puja, K. G., \& Kassimoto, T. (1994). Girls in Education and Pregnancy at School. In Z. Tumbo-Masabo \& R. Liliestrom (Eds). Chelewa Chelewa: The Dilemma of Teenage Girls Uppsala: The Scandinavian Institute of African Studies.

Rwezahura, T. P. (2005). The Role of Non-Governmental Organization (NGO) in Enhancing Access to Primary Schools in Tanzania. Unpublished M.A. (Ed) Dissertation. Dar es Salaam: University of Dar es Salaam.

URT. (2012). Basic Education Statistics in Tanzania: National Data. Dar es Salaam: Ministry of Education and Vocational Training.

Wood, C. (2002). Parent-Child Pre-School Activities can affect the Development of Literacy Skills. Journal of Research in Reading, 24, 248-265.

Woolfolk, A. (2004). Educational Psychology( $9^{\text {th }}$ Edition.). New York: Pearson Education Inc. Yin, R. K. (1994). Case Study Research: Design and Methods. London: Sage Publishers.

\section{Copyright Disclaimer}

Copyright for this article is retained by the author(s), with first publication rights granted to the journal.

This is an open-access article distributed under the terms and conditions of the Creative Commons Attribution license (http://creativecommons.org/licenses/by/3.0/). 